\title{
EL EUROCENTRISMO Y SUS AVATARES: LOS DILEMAS DE LAS CIENCIAS SOCIALES ${ }^{1}$
}

\author{
IMMANUEL WALLERSTEIN
}

Las ciencias sociales han sido eurocéntricas a lo largo de su Historia institucional, es decir, desde que han existido departamentos que han enseñando ciencias sociales dentro del sistema universitario. Esto no debe sorprendernos lo más mínimo. Las ciencias sociales son un producto del sistema-mundo moderno y el eurocentrismo es constitutivo de la geocultura del mundo moderno. Además, como estructura institucional, las ciencias sociales se originaron básicamente en Europa. Emplearemos aquí Europa más como una expresión cultural que cartográfica; en este sentido, cuando hablemos sobre los dos últimos siglos nos estaremos refiriendo principal y conjuntamente a Europa occidental y Norteamérica. Al menos hasta 1945, las disciplinas de las ciencias sociales estaban de hecho abrumadoramente localizadas en tan sólo cinco países: Francia, Gran Bretaña, Alemania, Italia y los Estados Unidos. Incluso hoy en día, a pesar de que las ciencias sociales han extendido su actividad globalmente, la gran mayoría de los científicos sociales del mundo siguen siendo europeos. Las ciencias sociales surgieron como respuesta a problemas zuropeos en un momento de la historia en el que Europa dominaba todo el sistema-mundo. Era prácticamente inevitable que la elección de su objeto, su teorización, su metodología y su apistemología reflejen todas las fuerzas del crisol en el que se forjaron. En el período posterior a ¿945, sin embargo, la descolonización de Asia y Africa y el incremento de la conciencia política de la totalidad del mundo no europeo han afectado al mundo del conocimiento tanto como a la política del sistema-mundo. Uno de los cambios fundamentales que se produjeron, y que perdura hasta hoy desde hace al menos treinta años, es que el 'eurocentrismo' de las ciencias sociales ha sido atacado, duramente atacado. Este ataque ha estado, por descontado, fundamentalmente ustificado, y no hay ninguna duda de que, si las ciencias sociales han de progresar en el siglo XXI, están obligadas a superar su herencia eurocéntrica, que ha tergiversado sus análisis y su apacidad de abordar los problemas del mundo contemporáneo. Si, no obstante. tenemos que zfectuar esta tarea, hemos de dilucidar cuidadosamente en qué consiste el eurocentrismo, ya que, como veremos, se trata de un monstruo de muchas cabezas que ha pasado por muchos avatares; 20 va a ser fácil matar al monstruo inmediatamente. De hecho, si no tenemos cuidado, bajo la sariencia del intento de combatirlo, podemos criticar el eurocentrismo utilizando premisas surocéntricas y, de ese modo, reforzar su influencia en la comunidad de estudiosos.

\footnotetext{
Exe texto constituye el discurso inaugural de la ISA East Asian Regional Colloquium, 'EI futuro de la sociología en el este de $\therefore$ sia. celcbrado el 22-23 de noviembre de 1996, en Seúl Corea, y coorganizado por la Asociación Coreana de Sociología y por la a wiación Internacional de Sociología.
} 


\section{I: LAS ACUSACIONES}

Se ha afirmado que el eurocentrismo de las ciencias sociales se ha manifestado de cinco formas diferentes. No constituyen un grupo estrictamente ordenado desde un punto de vista lógico. ya que se superponen entre sí de forma poco clara. A pesar de ello, puede resultar útil revisar las alegaciones dirigidas contra cada una de estas manifestaciones. Se ha argumentado que las ciencias sociales revelan su eurocentrismo: 1) en su historiografía; 2) en el provincianismo de su universalismo; 3 ) en sus presupuestos sobre la civilización (occidental); 4) en su orientalismo, ! 5) en sus intentos de imponer la teoría del progreso.

\section{Historiografía}

Consiste en la explicación del dominio europeo del mundo moderno mediante los logros específicos de la historia europea. Probablemente la historiografía sea fundamental para las otra explicaciones, pero asimismo es la variante más obviamente ingenua y aquella cuya validez más fácilmente puede cuestionarse. Sin duda alguna los europeos han estado durante los dos últimos siglos en la cima del mundo. Colectivamente, han controlado los países más ricos y los militarmente más poderosos. han disfrutado de la tecnología más avanzada y han sido los principales creadores de esta avanzada tecnología. Estos hechos parecen en gran medida incuestionables, y de hecho son difíciles de rebatir de modo verosímil. La cuestión es explicar el porqué de esta diferencia de poder y nivel de vida con el resto del mundo. Una posible respuesta es que los europeos han hecho algo meritorio y diferente de lo que han hecho los pueblos de otras partes del mundo. Esto es lo que defienden los estudiosos que hablan del milagro europeo?. Los europeos han impulsado la revolución industrial, han mantenido el crecimiento, han fundado la modernidad, el capitalismo. la burocratización o la libertad individual. Por descontado, tendremos que definir estos términos con mas detalle y descubrir si realmente fueron los europeos los que crearon estas novedades, sea cual fuere su contenido, y si es así, cuándo exactamente

Sin embargo, incluso si nos ponemos de acuerdo en la definición y en el momento y, por tanto, por decirlo así, en la realidad del fenómeno, de hecho hemos explicado muy poco. Pues también hemos de explicar por qué los europeos, y no otros, crearon estos fenómenos específicos y por qué lo hicieron en un momento determinado de la historia. Buscando estas explicaciones, la tendencia de la mayoría de los estudiosos ha sido remontarse en la historia buscando presuntos antecedentes. Si los europeos hicieron 'X' en el siglo XVI o XVIII, se entiende que ello ha sido así probablemente a causa de lo que sus antepasados (o sus supuestos antepasados, ya que la ascendencia es menos biológica que cultural, o pretendidamente cultural) hicieron o fueron en el siglo XI o en el $\mathrm{V}$ a.C. o incluso antes. Todos nosotros podemos pensar en diversas explicaciones que, una vez establecido o al menos asumido algún fenómeno ocurrido entre los siglos del XVI al XIX nos remontan a diversos momentos pasados de los ancestros europeos en búsqueda de la variable realmente determinante.

Aquí opera una premisa que no se ha hallado realmente oculta, pero que durante mucho tiempo no se ha debatido. Esta premisa es que cualquiera que sea la novedad de la que se responsabilice a Europa durante el período que media entre los siglos XVI y XIX, se trata de bueno, algo de lo que Europa debería enorgullecerse y algo que el resto del mundo debería envidiar

\footnotetext{
${ }^{2}$ Véase, por ejemplo E. L. Jones, The European Miracle: Environment. Economics and Geopolitics in the History of Europe and Asia, Cambridge.1981.
} 
o al menos apreciar. Esta novedad se percibe como un logro, y los títulos de numerosos libros dan testimonio de este tipo de evaluación.

Creo que no hay duda de que la historiografía real de las ciencias sociales mundiales ha expresado tal percepción de la realidad en un grado muy elevado. Esta percepción puede ser cuestionada, por supuesto aduciendo diversas razones de peso, y así se ha venido haciendo de modo cada vez mas intenso en décadas recientes. Se puede cuestionar la exactitud de la descripción de lo que ocurrió tanto en Europa como en el mundo entre los siglos XVI y XIX. Se puede ciertamente cuestionar la verosimilidad de los presuntos antecedentes culturales de lo que ocurrió en este período. Se puede insertar la historia de los siglos XVI-XIX en una duración mayor, extendiéndola a lo largo de varios siglos o decenas de miles de años. Si se hace esto, se afirmará habitualmente que los "logros" europeos de los siglos XVI-XIX parecen por ello menos notables o que forman parte en realidad de una variante cíclica, o incluso que puede atribuirse Europa. Por último, puede aceptarse que las novedades fueron reales, pero sostener que fueron un logro más negativo que positivo.

Esta clase de historiografía revisionista es a menudo persuasiva en su minuciosidad, y ciertamente tiende a ser acumulativa. En un momento dado, desenmascarar o deconstruir pueden llegar a ser omnipresentes, e incluso una contrateoría puede tener éxito. Esto es, por ejemplo, lo que parece estar pasando, o prácticamente ya ha ocurrido, con la historiografía de la Revolución Francesa, en la que, en cierto momento, se empezó a cuestionar las llamada interpretación social que había dominado la literatura especializada sobre la misma durante al menos siglo y medio, hasta que de alguna manera se destronó la mencionada interpretación durante los últimos treinta años. Hoy en día estamos entrando probablemente en uno de tales cambios de paradigma en la historiografía fundamental de la modernidad.

Cuando se produce un cambio de este tipo, sin embargo, deberíamos respirar hondo, volver atrás y evaluar si las hipótesis alternativas son de veras más plausibles y, por encima de todo, si en realidad rompen con las premisas esenciales de las anteriores hipótesis dominantes. Esta es la pregunta que quiero plantear en relación con la historiografía de los presuntos logros europeos en al mundo moderno. Esta siendo atacada. ¿Qué propuestas alternativas a la misma existen? ¿Y hasta qué puntos diferentes? No obstante, antes de abordar esta amplia cuestión, debemos revisar las otras criticas al eurocentrismo.

\section{Universalismo}

El universalismo es el punto de vista que sostiene que existen verdades científicas válidas an todo tiempo y lugar. El pensamiento europeo de estos últimos siglos ha sido en su casi totalidad marcadamente universalista. Se trataba de la era del triunfo cultural de la ciencia como actividad annoscitiva. La ciencia desplazó a la filosofía como la forma más prestigiosa de conocimiento y irbitro del discurso social. La ciencia a la que nos referimos es la ciencia de Newton y Descartes. Sus premisas eran que el mundo estaba gobernado por leyes deterministas que adoptaban la crma de procesos de equilibrio lineal y que, postulando estas leyes como ecuaciones reversibles ...niversales, tan sólo necesitábamos conocer además un conjunto dado de condiciones iniciales, ara que nos fuera posible predecir el estado del sistema en cualquier momento futuro o pasado.

Lo que esto significaba para el conocimiento social parecía evidente. Los científicos sociales indrían la posibilidad de descubrir los procesos universales que explican el comportamiento 
humano y cualquier hipótesis que pudiesen verificar se entendía que era válida en cualquier tiempo y lugar o debía enunciarse en términos tales que fuera cierta en cualquier tiempo y lugar. La persona del estudioso era irrelevante, ya que los estudiosos actuaban como analistas cuyos valores eran neutros. Y la ubicación de la evidencia empírica podía básicamente ignorarse con tal de que los datos fueran manejados de modo correcto, ya que se pensaba que los procesos eran constantes. La conclusiones no eran muy diferentes en el caso de aquellos estudiosos que preferían un acercamiento más histórico e ideológico, en tanto que se asumiera la existencia de un modelo subyacente de desarrollo histórico. Todos las teorías de las etapas (ya procedan de Comte, de Spencer o de Marx, por citar sólo algunos nombres de una larga lista) fueron principalmente teorización de lo que se ha dado en llamar la interpretación Whig de la historia, es decir, la presunción de que el presente es el mejor de los tiempos y de que el pasado llevaba inevitablemente al presente. E incluso los escritos históricos de marcada tendencia empirista, independientemente de cuánto proclamen su rechazo a teorizar, tendían de todos formas a reflejar inconscientemente una teoría de la etapas subyacente.

Ya sea en la forma ahistórica de un tiempo reversible de acuerdo con el modelo de los científicos sociales nomotéticos o ya sea en la forma diacrónica de la teoría de las etapas de los historiadores, las ciencias sociales europeas han sido resueltamente universalistas al afirmar que sea lo que fuere lo que ocurrió en Europa entre los siglos XVI y XIX, ello representó un modelo que era aplicable en todas partes, ya fuera porque suponía un logro progresivo irreversible de la humanidad o porque representaba la satisfacción de las necesidades humanas básicas mediante la eliminación de los obstáculos que se oponían a su realización. Lo que podía observarse entonces en Europa no era sólo bueno, sino el rostro del futuro que se desplegaría en todas partes.

Las teorías universalistas siempre han sido atacadas aduciendo que una situación particular en un momento y lugar particulares no parecía encajar en el modelo. Algunos estudiosos han argumentado también que las generalizaciones universalistas eran intrínsecamente imposibles. Sin embargo, en los últimos treinta años se ha lanzado un tercer ataque contra las teorías universalistas de las ciencias sociales modernas. Se ha sostenido la posibilidad de que estas teorías que se pretenden universales en realidad no lo sean, sino que sean una presentación del modelo histórico occidental tomado como universal. Joseph Needham señaló, ya hace algún tiempo, como "el error fundamental del eurocentrismo... el postulado tácito de que la ciencia y la tecnología modernas, que en realidad tienen sus raíces en la Europa del Renacimiento, son universales y que de eso se deduzca que todo lo que es europeo es universal" ${ }^{13}$.

Así, las ciencias sociales han sido acusadas de ser eurocéntricas en la medida en que eran particularistas. Y, más que eurocéntricas, se afirmaba que eran provincianas. Esta acusación golpeaba justo donde más dolía, ya que las ciencias sociales modernas se enorgullecían especialmente de haber superado cualquier provincianismo. En tanto que esta acusación parecía razonable, era mucho más convincente que afirmar nuevamente que las proposiciones universales todavía no habían sido formuladas de tal manera que pudieran explicar todos los casos.

\section{Civilización}

El término civilización se refiere a un grupo de características sociales que contrastan con el primitivismo o la barbarie. La Europa moderna se consideraba a sí misma algo más que una

Citado en La dialectique sociale. de Anouar Abdel-Malek, Paris 1972; traducido como Social Dialectics. vol I, Civilizations and Social Theory, Londres, 1981. (Existe edición en castellano: La dialéctica socia. Siglo XXI, Madrid) 
'civilización' entre varias: se consideraba la única 'civilizada' o aquella especialmente 'civilizada' Lo que caracterizaba este estado de civilización no es algo sobre lo que haya habido un consenso manifiesto ni siquiera entre los propios europeos. Para algunos, la civilización se hallaba englobada en la 'modernidad', esto es, en los avances de la tecnología y en el incremento de la productividad, así como en la creencia cultural en la existencia del desarrollo histórico y del progreso. Para otros, civilización significaba un incremento en la autonomía del 'individuo' frente a los demás actores sociales: la familia, la comunidad, el Estado, las instituciones religiosas. Para otros, civilización significaba un comportamiento no brutal en la vida cotidiana, modales sociales en el más amplio sentido de la palabra. Y. finalmente, para otros, civilización significaba reducir la esfera de la violencia legítima y ampliar la definición de crueldad. Y, por supuesto, para muchos, civilización incluía la combinación de algunos o de la totalidad de los rasgos mencionados.

Cuando los colonizadores franceses del siglo XIX hablaban de la misión civilisatrice, se referían a que, mediante la conquista colonial. Francia o, en general. Europa, impondrían a la población no europea los valores y las normas que estaban incluidos en estas definiciones de civilización. Cuando, durante la década de 1990, distintos grupos de países occidentales han hablado del 'derecho a la ingerencia' en situaciones políticas existentes en diversas partes del mundo, aunque casi siempre en zonas no occidentales, lo han hecho en nombre de tales valores de la civilización, que les conferían tal derecho.

Este conjunto de valores, con independencia de cómo prefiramos designarlos -valores civilizados, valores secular-humanistas, valores modernos-, impregna las ciencias sociales, como era de esperar, ya que éstas son producto del mismo sistema histórico que los ha elevado a lo más alto de la jerarquía vigente. Los científicos sociales han incorporado estos valores en sus definiciones de los problemas -los problemas sociales. los problemas intelectuales-, que consideran dignos de ser estudiados. Han incorporado estos valores a los conceptos que han inventado y con los que analizan estos problemas, así como a los indicadores que utilizan para medir los conceptos. En su mayoría, estos científicos sociales han insistido, sin duda, en que lo que pretendían era estar libres de valores, en tanto que han proclamado que sus preferencias sociopolíticas no les nacían tergiversar o malinterpretar los datos intencionadamente. Pero estar libre de valores en sste sentido no significa en absoluto que los valores, en el sentido de decisiones sobre la importancia histórica de los fenómenos observados, estén ausentes. Este, por supuesto. es el argumento central de Heinrich Rickert acerca de la especificidad lógica de lo que él denomina ciencias culturales ${ }^{4}$. Son incapaces de ignorar valores en el sentido de evaluar su importancia social.

Obviamente, las premisas occidentales y sociocientíficas sobre la 'civilización' no eran completamente insensibles al concepto de la multiplicidad de 'civilizaciones'. Cada vez que se planteaba la cuestión del origen de los valores civilizados, es decir, como es que éstos habían aparecido originalmente, al menos así se argumentaba. en el moderno mundo occidental, la respuesta casi inevitablemente era que esos valores eran producto de tendencias únicas e inmemorables inscritas en el pasado del mundo occidental, alternativamente descrito como la herencia de la Antigüedad y/o de la Edad Media cristiana, la herencia del mundo hebreo, o la nerencia combinada de ambos, esta última tambien rebautizada y recalificada, en ocasiones, como ¿. herencia judeo-cristiana

Se pueden plantear y se han planteado muchas objeciones a este conjunto de sucesivas zremisas. Se ha cuestionado si el mundo moderno o el mundo europeo moderno es civilizado, de

Feinrich Rickert, Die Gren-en der naturwissenschafflichem Begrihildung. Tubingen. 1913, traducido como The Limits of Concept Formution in the Physical Sciences, Cambridge. 1986. 
acuerdo con el propio sentido con el que la palabra se usa en el discurso europeo. Recuérdese el célebre sarcasmo de Mahatma Ghandi, quien. ante la pregunta: Sr. Ghandi, ¿qué piensa de la civilización occidental?, respondió: Sería una buena idea. Además, se ha discutido la afirmación de que los valores de la antigua Grecia y de la Roma antigua o del antiguo Israel fueran más propicios para servir de base para estos denominados valores modernos, que los valores de otras Civilizaciones antiguas. Y. por último, que la Europa moderna pueda señalar de una forma verosímil a Grecia o Roma, por un lado, o el antiguo Israel, por el otro, como su primer zócalo de civilización no es en absoluto obvio. De hecho, se ha prolongado durante mucho tiempo el debate entre aquellos que han contemplado Grecia o Israel como orígenes culturales alternativos. En este debate, cada bando ha negado la plausibilidad de la alternativa del otro. El debate mismo arroja dudas sobre la plausibilidad de tal derivación.

En cualquier caso. ¿quién discutiría que Japón pueda señalar a las antiguas civilizaciones del Indico como sus precursoras, basándose que fueron el lugar de origen del Budismo, que se han convertido un componente central de la historia cultural de Japón? ¿Están los actuales Estados Unidos más cerca culturalmente de la antigua Grecia, de Roma o de Israel que Japón de la civilización del índico'? Se podría aducir, después de todo, que la Cristiandad, lejos de representar una continuidad, marcó una ruptura decisiva con la antigua Grecia, con Roma y con Israel. En realidad, los cristianos, hasta el Renacimiento, utilizaron precisamente este mismo argumento. $Y$ ¿no es la ruptura con la Antigüedad aún hoy en día parte de la doctrina de las iglesias cristianas?

Sin embargo, actualmente, la esfera en la que la discusión sobre los valores ha alcanzado más intensidad ha sido la esfera política. El primer ministro de Malasia, Mahathir, ha sido muy específico al argumentar que los países asiáticos pueden y deben modernizarse sin aceptar todos o algunos de los valores de la civilización europea. Y sus puntos de vista han encontrado amplio eco en otros líderes políticos asiáticos. El debate sobre los valores también ha adquirido una importancia decisiva en los propios países europeos y especialmente en los Estados Unidos, bajo la forma del debate sobre el 'multiculturalismo'. Esta versión del debate actual ha tenido de hecho un gran impacto en las ciencias sociales institucionalizadas, con el florecimiento de estructuras dentro de la universidad que agrupan a los estudiosos que niegan la premisa de la singularidad de algo denominado "civilización".

\section{Orientalismo}

El orientalismo se refiere a una declaración estilizada y abstracta de las características de las civilizaciones no-occidentales. Es el anverso del concepto "civilización" y se ha convertido en tema fundamental en la discusión pública a partir de los escritos de Anouar Abdel Malek y Edward Said ${ }^{5}$ El orientalismo era hasta hace no mucho un signo de distinción ${ }^{6}$. Es un modo de conocimiento que tiene sus raíces en la Edad Media europea, cuando algunos monjes intelectuales cristianos se asignaron a sí mismos la tarea de comprender mejor las religiones no cristianas, aprendiendo sus lenguas y leyendo cuidadosamente sus textos religiosos. Por supuesto, partieron de la premisa de la verdad de la fe cristiana y del deseo de convertir a los paganos, pero de todas formas se tomaron los textos en serio, como expresiones, aunque pervertidas, de la cultura humana

Cuando el orientalismo se secularizó en el siglo XIX, la actividad se llevaba a cabo de una

\footnotetext{
${ }^{5}$ Abdel-Malck, la dialectique sociale; Edward Said. Orientalism. Nueva York, 1978, (Existe edición española: Orientalismo, Anagrama, Barcelona.)

"Véase Wilfred Cantwell Smith, "The place of Oriental Studies in a University". Diógenes, núm. 16, pp 106-111.
} 
forma que no era muy diferente. Los orientalistas continuaban aprendiendo las lenguas y descifrando los textos. Durante el proceso, contimuaban basándose en una visión binaria del mundo social. En lugar de la distinción cristiano/pagano, colocaron la distinción occidental/oriental, o la de moderno/no moderno. En las ciencias sociales emergió una larga cadena de conocidas polaridades: sociedades militares e industriales, Gemeinschaft y Gesellschaft, solidaridad mecánica y orgánica, legitimación tradicional y racional-legal, estática y dinámica. Aunque frecuentemente estas polaridades no se relacionaban directamente con la literatura sobre el orientalismo, no deberíamos olvidar que una de las primeras polaridades fue la de estatus y contrato de Maine, que se basaba explícitamente en una comparación de los sistemas legales hindú e inglés.

Los orientalistas se veían a sí mismos como personas que expresaban su benevolente aprecio por una civilización no occidental dedicando diligentemente sus vidas al estudio erudito de los textos para comprender (verstehen) la cultura. La cultura que comprendían de esta manera era, claro está, un constructo fabricado por alguien que provenía de una cultura distinta. La validez de estos constructos se ha puesto en tela de juicio a tres diferentes niveles: se ha dicho que los conceptos no coinciden con la realidad empírica; que abstraen demasiado y por tanto, eliminan la rariedad empírica, y que son extrapolaciones de los prejuicios europeos

El ataque contra el orientalismo fue, de todas formas, algo más que un ataque contra las carencias de esa disciplina académica. También fue una critica de las consecuencias políticas de estos conceptos de las ciencias sociales. Se dijo que el orientalismo legitimaba la posición de Europa como potencia dominante, y que de hecho, se han discutido algunos intentos no occidentales de crear un contradiscurso de "occidentalismo" y se ha sostenido por ejemplo, que todos los discursos elitistas del antitradicionalismo en la China moderna, desde el Movimiento del 4 de mayo hasta las manifestaciones de los estudiantes de 1989 en la plaza de Tiannamen, han estado ampliamente orientalizados ${ }^{7}$, lo cual ha servido para sostener el orientalismo, en lugar de socavarlo.

\section{Progreso}

El progreso, su realidad, su inevitabilidad. fue un tema fundamental de la ilustración europea. Hay quien lo remite a toda la filosofía occidental ${ }^{5}$. En cualquier caso, se convirtió en el punto de vista consensuado de la Europa del siglo XIX, tal y como fueron creadas, estuvieron profundamente marcadas por la teoría del progreso.

El progreso se convirtió en la explicación subyacente de la historia del mundo, y en el fundamento racional de casi todas las teorías de las etapas. Incluso se convirtió en el motor de todas las ciencias sociales aplicada. Se nos decía que debíamos estudiar ciencias sociales para entender mejor el mundo social, ya que así podríamos impulsar el progreso de una forma más sabia y acelerar su ritmo de un modo más seguro en cualquier parte o, al menos, ayudar a eliminar lus obstáculos que se interponen en su camino. Las metáforas de la evolución o del desarrolio no zran meros intentos de describir; eran también incentivos para prescribir, las ciencias sociales se convirtieron en el consejero, a veces incluso en la criada, de los responsables políticos, desde el panopticon de Bentham, pasando por la Verein fur So-ialipolitik, hasta el Beveridge Report y tras innumerables comisiones gubernamentales, de las series sobre el racismo de la UNESCO tras la Segunda Guerra Mundial, hasta las sucesivas investigaciones de James Coleman sobre el

Xianomei Chen "Occidentalism as Counterdiscourse: "HeShang" in Post Mto China. Critical Inquiry, vol.18. nú4, verano 1992, p. 687.

1.B. Bury. The Idea of Progress, Londres. 1920: Robert A. Yistat. History of the Idea of Progress, Nueva York, 1980 
sistema educativo estadounidense. Tras la Segunda Guerra Mundial, "el desarrollo de los países subdesarrollados" constituyó una rúbrica que justificaba el compromiso de científicos sociales de cualquier opción política con la reorganización social y política del mundo no occidental.

El progreso no sólo se asumió o analizó, también se impuso. Esto quizá no difiere demasiado de las actitudes que estudiamos bajo el epígrafe de "civilización". Lo que ha de subrayarse es que, en el momento en que la categoría de "civilización", empezó a ser una categoría que había perdido su inocencia y atraído sospechas, básicamente a partir de 1945, el "progreso" sobrevivió como categoría y fue más que adecuada para sustituir a la "civilización", ya que olía algo mejor. La idea del progreso parecía servir como el último reducto del eurocentrismo, como posición de retirada defensiva.

La idea de progreso ha tenido siempre, por supuesto, sus críticos conservadores, aunque se puede decir que la fuerza de su resistencia decreció drásticamente durante el período 1850 1950. Sin embargo, al menos desde 1968, han surgido muchos críticos de la idea de progreso: entre los conservadores con renovadas fuerzas, y entre la izquierda con una fe recién descubierta. Existen, no obstante, muchas maneras distintas de atacar la idea de progreso Se puede sugerir que lo que se ha llamado progreso es un falso progreso, pero que existe un progreso real, aduciendo que la versión Europa era un engaño o un intento de engañar. O puede sugerirse que no existe esa cosa llamada progreso, debido al "pecado original" o al ciclo eterno de la humanidad. O se puede sugerir que Europa ha conocido realmente el progreso, pero que ahora está intentando alejar al resto del mundo de los frutos del mismo, como han sostenido algunos críticos no occidentales del movimiento ecologista.

Lo que si es evidente para muchos es que la idea de progreso se ha identificado como una idea europea, hecho por el que ha sido atacada por su eurocentrismo. Este ataque ha sido, sin embargo, muy contradictorio, dados los esfuerzos realizados por otros no occidentales por apropiarse del progreso, expulsando a Europa de la escena, pero no al progreso.

\section{LAS REIVINDICACIONES DEL ANTIEUROCENTRISMO}

Las múltiples formas de eurocentrismo y de crítica al eurocentrismo no presentan necesariamente un cuadro coherente. Intentaremos evaluar el debate fundamental. Como hemos observado, las ciencias sociales institucionalizadas empezaron su actividad en Europa. Se las ha acusado de dibujar una descripción falsa de la realidad social mal interpretando, exagerando en gran medida y/o distorsionando el papel histórico de Europa, particularmente su papel histórico en el mundo moderno.

Los críticos plantean generalmente tres reivindicaciones diferentes, en cierto sentido contradictorias. La primera es que con independencia de lo que hizo Europa, otras civilizaciones lo estaban haciendo, hasta que Europa empleó su poder geopolítico para interrumpir este proceso en otras partes el mundo. La segunda es que lo que Europa hizo no es sino la continuación de lo que otros ya estaban haciendo durante mucho tiempo, incorporándose los europeos en un momento determinado al primer plano. La tercera es que lo que Europa hizo se ha analizado incorrectamente y ha sido objeto de extrapolaciones inapropiadas, que a su vez han tenido consecuencias peligrosas tanto para la ciencia como para el mundo político. Los dos primeros argumentos, ampliamente representados, me parece que adolecen de lo que yo llamaría "eurocentrismo antieureocéntrico". 
El tercero me parece indudablemente correct o y se merece que le prestemos toda nuestra atención. ¿Qué clase de extraño animal es ese "eurocentrismo antieurocéntico"? Estudiemos cada uno de estos argumentos sucesivamente.

\section{El primero que llega a la meta}

A lo largo del siglo XX, hay quien ha sostenido que en el marco de, por ejemplo la "civilización" china, india o árabe-musulmán, existían tanto los fundamentos culturales, como la pauta sociohistórica de desarrollo, que hubieran llevado a la emergencia del capitalismo moderno con todas sus características, o que, en realidad, tales civilizaciones se hallaban inmersas en el proceso que las conducía en esa dirección. En el caso de Japón, el argumento cobra más fuerza incluso, afirmándose que el capitalismo moderno se desarrolló allí, independientemente, pero coincidiendo en el tiempo con su desarrollo en Europa. El núcleo de la mayoría de estos argumentos está constituido por la teoría de las etapas del desarrollo. frecuentemente en su versión marxista, de la cual se deduce lógicamente que diferentes partes del mundo seguían caminos paralelos hacía la modernidad o el capitalismo. Este tipo de argumento presuponía tanto la especificidad y la autonomía social de las distintas regiones civilizadas del mundo, por un lado, y su común subordinación a un modelo omnicomprensivo, por otro.

Dado que todas las discusiones de este tipo se refieren específicamente a una determinada zona cultural y a su desarrollo histórico, sería un ejercicio imponente discutir la verosimilitud histórica de cada caso, y no pretendo hacerlo aquí. Lo que quiero destacar es que existe una limitación lógica a esta línea de argumentación, con independencia de la región de la que hablemos, Y una consecuencia intelectual general. La limitación lógica es bastante obvia. Incluso si fuera cierto que algunas otras partes del mundo hubieran estado avanzando por el camino de la modernidad/capitalismo o quizá hubieran avanzado tremendamente en el mismo, esta argumentación nos deja todavía con el problema de explicar el hecho de que fuera Occidente, o Europa, quien alcanzó primero el objetivo y, por tanto, quien pudo "conquistar el mundo". En este punto volvemos a la pregunta tal y como la planteamos originalmente: ¿por qué la modernidad/ el capitalismo en Occidente?

Por supuesto, en la actualidad hay quien niega que Europa conquistara el mundo en el sentido estricto de la palabra, aduciendo que siempre ha habido resistencia; a mi juicio, creo que esto fuerza nuestra lectura de la realidad. Hubo después de todo, una conquista colonial real que cubrió una gran porción del globo. Existen, después de todo, auténticos indicadores militares de la fuerza europea. Sin duda siempre existieron diversas formas de resistencia, activas y pasivas, pero si esta resistencia hubiera sido verdaderamente tan formidable, no tendríamos en la actualidad nada que discutir al respecto. Si insistimos demasiado en el tema de una agencia no europea acabaremos lavando todos los pecados europeos o, al menos, la mayoría. No me parece que sea ésta la intención de los críticos.

En cualquier caso, independientemente de lo transitoria que consideremos la dominación europea, aún tenemos que explicarla. La mayoría de los críticos que siguen esta línea de argumentación tiene más interés en explicar cómo Europa interrumpió un proceso indígena en la parte del mundo objeto de su consideración, que en explicar cómo es que Europa fue capaz de hacerlo. Aún más, intentando disminuir los méritos de Europa por este hecho, por este presunto "logro", refuerzan la idea de que fue un logro. La teoría convierte a Europa en un "héroe villano": villano, sin duda, pero también sin duda héroe en el sentido más dramático del término, pues fue 
Europa la que hizo el esfuerzo final de la carrera y cruzó la línea de llegada en primer lugar. Y. aún peor, existe la implicación, no demasiado lejos de la superficie. de que, si hubieran tenido la oportunidad los chinos. los indios o los árabes no sólo habrían fundado la modernidad/capitalismo, conquistando el mundo, explotando recursos y personas y adoptado también el papel del héroe villano.

Esta visión de la historia moderna parece ser muy eurocéntrica en su antieurocentrismo. ya que acepta la importancia, esto es, el valor, de los "logros" europeos precisamente en los mismos términos con que Europa los ha definido. y afirma tan sólo que otros podrían haberlo hecho también, o que también estaban haciéndolo. Probablemente por alguna razón accidental, Europa logró una ventaja temporal e interfirió en su desarrollo por la fuerza. La afirmación de que otros también podrían haber sido europeos me parece una forma muy débil de oponerse al eurocentrismo que, en realidad, refuerza las peores consecuencias del pensamiento eurocéntrico sobre el conocimiento social.

\section{Capitalismo eterno}

La segunda línea de oposición a los análisis eurocéntricos es aquella que niega que hubiera algo realmente nuevo en lo que Europa hizo. Este argumente empieza por destacar que en la Baja Edad Media, e incluso desde mucho tiempo antes, Europa occidental era un área marginal y periférica del continente eurasiático, cuyo papel histórico y logros culturales estaban por debajo de los de otras partes del mundo. como Arabia o China. Esto es indudablemente cierto, al menos en un primer nivel de generalización. Después, se da un rápido salto para situar a la Europa moderna dentro de la construcción de una ecúmene o estructura-mundo que se ha estado creando durante varios miles de años ${ }^{9}$. Esto no es inverosímil. pero en mi opinión, la significación sistemática de esta ecúmene aún tiene que ser dilucidada. Es ahora cuando llegamos al tercer elemento de la secuencia. Que la inicial marginalidad de Europa accidental, no era nada especial, sino tan sólo una variante más en la construcción histórica de un sistema singular.

Este último argumento me parece conceptual e históricamente totalmente erróneo. No es mi intención, sin embargo. volver sobre el $1^{1 "}$. Tan sólo deseo subrayar las formas en que este argumento es otra forma de eurocentrismo antieurocéntrico. Lógicamente, implica suponer que el capitalismo no es nada nuevo. y, de hecho, algunos de los que defienden la continuidad del desarrollo de la ecúmene eurasiática han adoptado explícitamente esta posición. A diferencia de la posición de aquellos que sostenían que alguna otra civilización se dirigía también hacía el capitalismo cuando Europa interfirió en este proceso, el argumento que se aduce aquí es que todos nosotros estábamos realizando esta tarea conjuntamente. y que en realidad no ha habido un desarrollo hacia el capitalismo en los tiempos modernos. porque el mundo en su conjunto, o por lo menos toda la ecúmene eurasiática. había sido capitalista en algún sentido durante varios miles de años.

Permítaseme indicar, en primer lugar, que ésta es la posición clásica de los economistas liberales. No difiere mucho en realidad de Adam Smith cuando sostiene que existe una propensión

\footnotetext{
"Véanse varios autores en Stephen K. Sanderson. Civilizations and World Systems: Studying World-Historical Change. Wainut Creek, CA. 1995.

${ }^{10}$ Immanuel Widlerstein, "The West. Capitalism and the Yodern World-System". Review, vol XV. núm 4. otono de 1902, pp 561 619.
} 
- en la naturaleza humana) a trocar. permutar e intercambiar una cosa por otra ${ }^{11}$. Elimina diferencias esenciales entre sistemas históricos distintos. Si los chinos los egipcios y los europeos occidentales han estado haciendo lo mismo históricamente, ¿en qué sentido son civilizaciones diferentes o sistemas históricos distintos?! Q Quitándole méritos a Europa, ¿a quién concedérselos sino a toda la humanidad?

Sin embargo. y es lo peor de todo, al apropiarnos de lo que la modema Europa hizo y anotarlo en el balance de la ecúmene eurasiático estamos aceptando el argumento ideológico esencial del eurocentrismo: que la modernidad, o el capitalismo, es milagroso y maravilloso, tan sólo añadiendo que todo el mundo siempre lo ha estado practicando siempre de una u otra manera. Al negar el mérito de Europa, negamos su culpa. ¿.por qué es tan terrible la 'conquista del mundo' nor parte de Europa, si no se trata de nada más que el último tramo del proceso inexorable de la ecúmene? Lejos de ser un argumento crítico con Europa. implica aplaudir el que Europa, habiendo ido una parte 'marginal ' de la ecúmene. aprendiera finalmente la sabiduria de los otros, más antiguos, y la aplicara con éxito.

Y de ello se desprende inevitablemente el siguiente argumento no explicitado. Si la ecúmene eurasiática ha seguido un hilo conductor durante miles de años y el sistema mundo-capitalista no es nada nuevo, entonces. ¿qué posible razón existe para afirmar que este hilo no continuará para siempre o, al menos durante un larguísimo e indefinido período de tiempo? Si el capitalismo no empezó en el siglo XVI, o en el XVIII, no es probable que acabe en el siglo XXI. Personalmente, no lo creo, $y$ he tratado el asunto en varios escritos recientes ${ }^{13}$. Mi argumento principal es que esta línea de razonamiento no es en absoluto antieurocéntrica, ya que acepta el conjunto básico de valores propuesto por Europa en su período de dominación mundial y, por consiguiente, niega y/ o infravalora los sistemas de valores rivales que estaban o están vigentes en otras partes del mundo.

\section{El análisis del desarrollo europeo.}

Creo que tenemos que encontrar bases mas sólidas para ir contra el eurocentrismo en las ciencias sociales, así como caminos más sólidos para perseguir este objetivo. La tercera forma de crítica -que todo lo que Europa ha hecho se ha analizado de forma incorrecta y ha sido objeto de extrapolaciones inapropiadas, que han tenido consecuencias peligrosas tanto para la ciencia como para el mundo político- en realidad es cierta. Creo que hemos de empezar por cuestionarnos la presunción de que lo que Europa hizo fue positivo. Creo que hemos de establecer un cuidadoso balance de situación de lo que ha conseguido la civilización capitalista durante su vida histórica, y valorar si los beneficios son mayores que los perjuicios. Esto es algo que ya intenté en una casión, y que animo a otros a hacer ${ }^{1+}$ Mi propio balance es totalmente negativo y, por tanto, no considero al capitalismo como una prueba del progreso humano. Por el contrario, lo considero consecuencia de una ruptura de las barreras históricas contra esta particular versión de un sistema explotador. Considero que el hecho de que China, la India, el mundo árabe y otras regiones no se

Adam Smith, The Wealth of the Nations 1776. Nueva York. 1939. p.13. Existe edición en castellano la riqueza de las naciones. Alianza Editorial, Madrid.

Para un punto de vista opuesto véase Samir Amin. 'The Ancient World-Systems versus the Modern Capitalist World'. Review, wiXIV. núm. 3, verano de 1991.pp 349-385

Immanuel Wallerstein. After Liberalism, Nueva York. 1995: Terence K. Hopkins e Immanuel Wallerstein, coord. The Age of Transition: Trajectory of the World-System. 1945-2025.Londres, 1996.

Vase Immanuel Wallerstein, "Capitalist Civilization", Wei Lun Lecture Series II. Chinese University Bulletin. núm. 23, reprodu-ito en Historical Capitalism. with Capitalist Civilization. Verso, Londres. 1995. 
hayan dirigido directamente hacia el capitalismo es una prueba de que estaban, y eso es mérito histórico suyo, mejor inmunizadas contra la toxina. Transformar su mérito en algo que deben justificar, supone para mí la quintaesencia del eurocentrismo.

Permítaseme explicarme mejor. Creo que en los sistemas históricos (civilizaciones) más importantes ha existido siempre un cierto nivel de mercantilización y, por tanto, de comercialización. En consecuencia, siempre ha habido personas que buscaban beneficios en el mercado. Pero existe una diferencia abismal entre un sistema histórico en el que existen algunos empresarios o mercaderes o 'capitalistas', y otro en el que dominan el ethos y la práctica capitalista. Antes del sistema-mundo moderno lo que ocurría en cada uno de estos otros sistemas históricos es que en el momento en que un estrato capitalista se hacia demasiado rico o tenía demasiado éxito o adquiría demasiada influencia sobre las instituciones existentes, otros grupos institucionales, culturales, religiosos, militares o políticos lo atacaban, utilizando tanto su importante cuota de poder como sus sistemas de valores para afirmar la necesidad de contener y refrenar al estrato orientado hacia el beneficio. El resultado es que estos estratos vieron malogrados sus intentos de imponer sus prácticas en el sistema histórico como una prioridad. En ocasiones, se les arrebató cruel y brutalmente el capital acumulado y, en cualquier caso, se les obligó a obedecer a los valores y las prácticas que les mantenían a raya. A esto es a lo que me refiero cuando hablo de las antitoxinas que contuvieron el virus.

Lo que ocurrió en el mundo occidental fue que por una serie específica de razones momentáneas, o coyunturales, o accidentales, las antitoxinas fueron más difíciles de encontrar y menos eficaces, y el virus se extendió con rapidez mostrándose invulnerable a posteriores intentos de revertir sus efectos. La economía-mundo europea del siglo XVI se convirtió irremediablemente en capitalista. Y una vez que el capitalismo se consolidó en este sistema histórico, una vez que este sistema se rigió por la prioridad de la incesante acumulación de capital, adquirió tal fuerza contra otros sistemas históricos, que ello le permitió expandirse geográficamente hasta absorber físicamente todo el globo, convirtiéndose en el primer sistema histórico que lograba este tipo de expansión total. El hecho de que el capitalismo lograra esta clase de ruptura en el ámbito europeo y de que después se expandiera hasta cubrir el globo no significa. sin embargo, que esto fuera inevitable, deseable o que en cualquier sentido supusiese un progreso. En mi opinión, no fue nada de eso, y un punto de vista antieurocéntrico debe empezar por afirmarlo.

Preferiría, por consiguiente, reconsiderar to que no es universalista en las doctrinas universalistas que han surgido a partir de ese sistema histórico que es capitalista, nuestro moderno sistema-mundo. El sistema-mundo moderno ha desarrollado estructuras de conocimiento significativamente distintas de las anteriores estructuras de conocimiento. Se dice a menudo que lo que es diferente es el desarrollo del pensamiento científico. Parece evidente, sin embargo, que esto no es cierto, independientemente de lo espléndidos que sean los modernos avances científicos. El pensamiento científico antecede ampliamente al mundo moderno y está presente en la totalidad de las principales zonas civilizatorias. Todo esto ha sido magistralmente demostrado para el caso de China, por el conjunto de la obra de Joseph Needham ${ }^{15}$.

Lo que sí es específico de las estructuras del sistema-mundo moderno, por el contrario, es el concepto de las "dos culturas". Ningún otro sistema histórico ha instituido un divorcio fundamental entre la ciencia, por un lado, y la filosofía y las humanidades, por el otro; lo cual creo que se caracterizaría mejor describiéndolo como la separación entre la búsqueda de la verdad

\footnotetext{
${ }^{15}$ Joseph Needham. Sciencies and Civilization in China. Cambridge. 1954. y otras obras posteriores del mismo autor.
} 
Y la búsqueda de lo bueno y de lo bello. En realidad, no fue tan sencillo incluir este divorcio en la geocultura del moderno sistema-mundo. Se necesitaron tres siglos antes de que la escisión se institucionalizara. En nuestros días, sin embargo, constituye un rasgo fundamental de la geocultura actual y forma la base de nuestros sistemas universitarios.

Esta escisión conceptual ha permitido que el mundo moderno concibiese ese extraño concepto del especialista no afectado por sus valores, cuyas valoraciones objetivas de la realidad podrían conformar la base no sólo de las decisiones técnico-organizativas, en el más amplio sentido del término, sino también de las decisiones sociopolíticas. Al proteger a los científicos de la valoración colectiva, $y$, en realidad, al fundirlos con los tecnócratas, se liberó a los científicos de la mano muerta de una autoridad intelectualmente irrelevante. Pero, simultáneamente, ello evitó que las mayores y más fundamentales decisiones sociales que hemos tomado durante los últimos 500 años fueran objeto de un debate científico sustantivo, es decir, no técnico. La idea de que la ciencia esta en un lado y las decisiones políticas en otro es el concepto central que sostiene al eurocentrismo, ya que las únicas proposiciones universalistas que han sido aceptables son aquellas que son eurocéntricas. Cualquier argumento que refuerce esta separación de las dos culturas sostiene, por tanto. el eurocentrismo. Si se niega la especificidad del mundo moderno, no hay ninguna forma plausible de debatir la reconstrucción de las estructuras del conocimiento y, por lo tanto, ninguna forma plausible de alcanzar alternativas inteligentes y sustancialmente racionales al sistema-mundo existente.

Durante los últimos veinte años, la legitimidad de este divorcio ha sido puesta en duda por rez primera de una forma significativa. Este, por ejemplo, es el sentido del movimiento ecologista. Y éste es el tema central que subyace en el ataque público contra el eurocentrismo. Los desafíos han producido las llamadas "guerras entre las ciencias" y "guerras entre las culturas", que muy a menudo han sido oscurantistas y ofuscantes. Si debemos dotarnos de una estructura de conocimiento reunificada y, por tanto no eurocéntrica, es absolutamente esencial que no nos desviemos por caminos secundarios, que evitan este problema central. Si tenemos que construir un sistema-mundo alternativo al actual que se halla inmerso en una fuerte crisis, debemos tratar simultáneamente e inextricablemente los problemas de lo que es verdad y lo que es bueno.

Y si queremos lograrlo, hemos de reconocer que Europa hizo algo especial entre los siglos KVI y XVIII que transformó el mundo, pero en una dirección cuyas consecuencias negativas estamos sufriendo ahora. No debemos acometer el intento de privar a Europa de su especifidad aduciendo la falsa premisa de que estamos así privándola de un mérito ilegitimo. Todo lo contrario. Debemos reconocer abiertamente la particularidad de la reconstrucción del mundo por Europa, pues sólo entonces será posible superarla y alcanzar una visión más inclusivamente universalista de las posibilidades humanas, que no evite ninguno de los intrincados y complejos problemas que supone buscar simultáneamente lo que es verdad y lo que es bueno. 